\title{
EFFECT OF ANAESTHETIC AGENTS ON THE IONIC COMPOSITION OF CEREBROSPINAL FLUID FOLLOWING TOTAL CEREBRAL ISCHAEMIA
}

\author{
JoHn G. WADE AND SøREN C. SqRENSSON
}

THE BARBITURATES have been shown to protect the brain against cerebral ischaemia. ${ }^{1}$ On the other hand, halothane has been shown to offer no protection against cerebral ischaemia and is perhaps deleterious. ${ }^{2}$ It is known that total cerebral ischaemia produces a marked increase in cerebrospinal fluid (CSF) potassium concentration and it has been speculated that such a marked rise in interstitial potassium might reduce the reperfusion of the ischaemic brain by constricting the cerebral arterioles. ${ }^{3.4}$ Hypothermia, which protects ischaemia brain, has been shown to delay and to slow the rise in CSF potassium following cerebral ischaemia. The mechanism by which barbiturate, but not halothane anaesthesia, protects against cerebral ischaemia might be attributed to different effects on interstitial, perivascular, and CSF ionic composition following cerebral ischaemia.

The purpose of this study was to compare the effects of three anaesthetic techniques: (1) halothane oxygen, (2) pentobarbitone, (3) nitrous oxide/oxygen/relaxant - on the ionic composition of the cisternal CSF of the rat following total cerebral ischaemia.

\section{METHODS}

The three anaesthetic techniques were utilized: (1) halothane two per cent in oxygen; (2) pentobarbitone 50 to $75 \mathrm{mg} / \mathrm{kg}$ injected into the peritoneal space; (3) halothane/ox ygen for induction only and maintenance with 70 per cent nitrous oxide in oxygen with curare $6 \mathrm{mg} / \mathrm{kg}$ for muscle relaxation.

A total of 73 male Wistar strain rats each weighing approximately $450 \mathrm{~g}$ were studied. After induction of anaesthesia a tracheostomy was done and the animals were ventilated with a constant volume respirator adjusted to maintain the arte-

John G. Wade, M.D., Department of Anaesthesia, University of Manitoba. Søren C. Sqrenson, M.D., Institute of Medical Physiology, University of Copenhagen.

Address communications to: John G. Wade, M.D. Department of Anaesthesia, Health Sciences Centre. 700 William Ave., Winnipeg, Manitoba, R3E 0Z3. rial $\mathrm{PaCO}_{2}$ between 35 and 40 torr. The rectal temperature was maintained at $37.5 \pm 0.5^{\circ} \mathrm{C}$ by means of a heating pad. A polyethylene catheter was inserted into the abdominal aorta and was used to measure arterial blood pressure continuously.

The thorax was opened broadly by cutting the ribs on both sides of the sternum, which enabled a free exposure of the heart and major vessels. Silk threads were placed around the ascending aorta close to the heart. In order to produce cerebral ischaemia the circulation was arrested by occluding the arterial outflow from the heart. The completeness of the occlusion was ascertained by monitoring the pressure in the aorta. $A$ drop in arterial pressure to approximately 10 torr was always observed within seconds. A sample of cerebrospinal fluid was obtained by cisternal puncture during the control period or after 2,8 , or 16 minutes of cerebral ischaemia. In the nitrous oxide/oxygen/relaxant group an interval of at least $\mathbf{3 0}$ minutes was allowed between the brief halothane induction and CSF sampling to ensure adequate halothane washout.

The cisternal cerebrospinal fluid sample was obtained with a glass capillary after exposing the atlanto-occipital membrane. The concentrations of potassium and sodium in CSF were measured by flame photometry and the concentration of chloride by coulomb-metric titration. A micropipetting system (Siggard-Anderson) was used for sample and reagents. ${ }^{4}$ All analyses were performed in duplicate.

The two-sample test for unpaired observations was used to analyze the data, $P$ values were determined by Student's t-test distribution. $\mathrm{P}<$ 0.05 was considered significant.

\section{RESULTS}

Table I compares the ionic composition of the CSF following cerebral ischaemia in the three groups of rats. The most striking finding is a marked and significant rise in CSF potassium, which is also illustrated in Figure 1. There was no aignificant difference in the increase of the CSF 


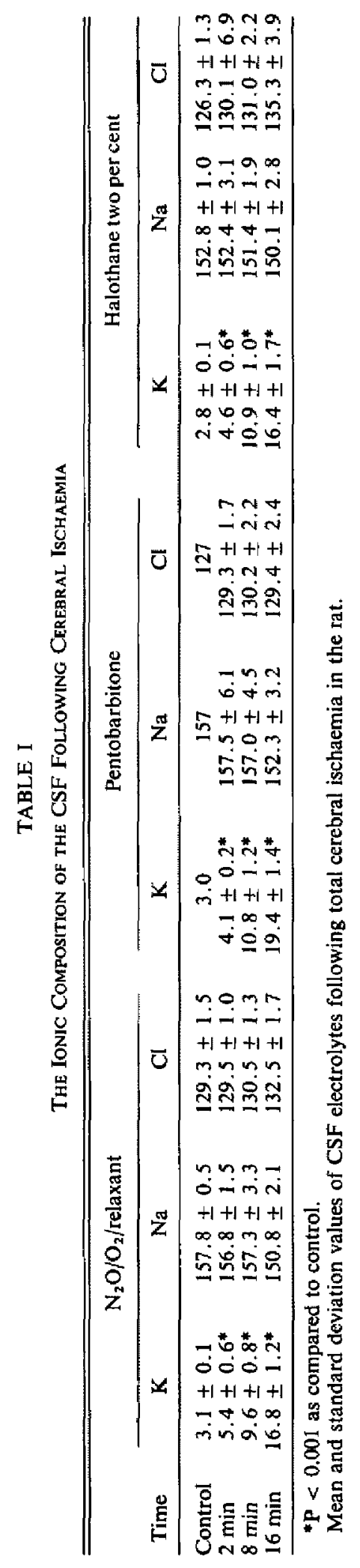




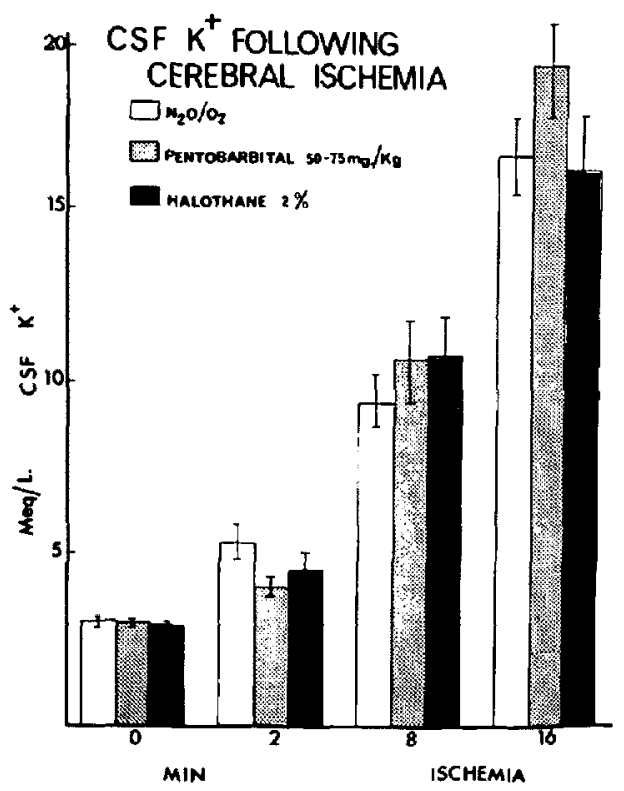

Figure 1. Cisternal CSF potassium concentration following total cerebral ischaemia.

potassium concentration between the three anaesthetic techniques studied.

There were no significant changes in CSF sodium and chloride concentrations following ischaemia.

\section{Discussion}

We have found a marked increase in the potassium concentration of the cisternal CSF following total cerebral ischaemia, confirming our previous studies. ${ }^{3,4}$ In addition we have found that the anaesthetic techniques studied had no effect on the CSF potassium concentration following cerebral ischaemia.

The maintenance of normal ionic composition of the extra-cellular fluid and of the directly communicating CSF is dependent on the metabolic processes which remove or exclude sodium from the cells (the "sodium pump"). The fuel for this pump is ATP which is produced from oxygen and substrate delivered by the cerebral circulation. Total cerebral ischaemia deprives the "pump" of ATP. The cerebral cells are no longer able to maintain their ionic concentration gradients. Potassium will passively leak out from cells while sodium and water will enter cells. The increased extracellular potassium concentration in brain will be reffected in the directly communicating CSF but will be delayed according to diffusion distances which, in the rat, are relatively small.

The increased potassium concentration in the extracellular fluid of brain and in CSF is an index of the severity of the ischaemic episode and has been suggested as an indicator of brain damage. As a secondary effect the increased CSF potassium concentration might influence the cerebrovascular resistance.

Both the barbiturates and hypothermia' protect the brain from cerebral ischaemia. Bering studied the effects of hypothermia and circulatory arrest on cerebrospinal fluid electrolyte composition in the dog. ${ }^{5}$ He found that hypothermia itself, like the anaesthetic techniques we studied, produced no change in ionic CSF composition. Like us he found that brain ischaemia caused changes mainly in the potassium concentration of the CSF. However, hypothermia caused a delay in the increase of CSF potassium and the rate of rise of CSF potassium was increasingly slower at lower temperatures.

We found no difference in the CSF potassium increase when comparing pentobarbitone anaesthesia, halothane anaesthesia and nitrous oxide/ oxygen/relaxant anaesthesia.

We conclude that the mechanism of ischaemic brain protection with the barbiturates is different from hypothermia. However, our studies were of the CSF ionic composition. More sophisticated techniques such as the interstitial potassiumelectrode should stimulate more precise studies in the future.

\section{SUMMARY}

Total cerebral ischaemia in rats caused a marked increase in the cisternal CSF potassium concentration but little change in CSF sodium or chloride concentration. The anaesthetic techniques studied (pentobarbitone, halothane/oxygen and nitrous oxide/oxygen/relaxant) did not effect the potassium increase following cerebral ischaemia. We conclude that the mechanism of barbiturate protection following cerebral ischaemia is different from that of hypothermia.

\section{RÉSUMÉ}

Une ischémie cérébrale totale chez le rat amène une augmentation marquée du potassium tel que déterminé dans le LCR cisternal, et ne cause que peu de changements des chlorures et 
du sodium au niveau du LCR. Nous avons étudié l'influence de certains anesthésiques (pentobarbital, halothane-oxygène, protoxyde-oxygène) sur l'élévation du potassium après ischémie cérébrale totale. Nous avons trouvé que les agents étudiés ne modifiaient pas les résultats. Nous concluons que les barbituriques qui confèrent une protection contre l'ischémie cérébrale le font par un mécanisme différent de celui de l'hypothermie.

\section{REFERENCES}

1. Michenfelder, J.D. \& Milde, J.H. Cerebral protection by anaesthetics during ischaemia (a review). Resuscitation 4: 219-233 (1976).
2. SMITH, A. L., et al. Barbiturate protection in acute focal cerebral ischaemia. Stroke 5: 1-7(1974).

3. WAde, J., AMTORP, O., \& Sorenson, S.C. Increase in the potassium concentration in brain extracellular fluid as a cause of the "no-flow" state following cerebral ischemia. Acta Physiologica Scand. 91: 49A-50A (1974).

4. WAde, J.G., AmTorP, O., \& SøRenson, S.C No-fiow state following cerebral ischemia: role of increase in potassium concentration in brain interstitial fluid. Arch. Neurol. 32: 381-384 (1975),

5. BERING, E.A. Effects of profound hypothermia and circulatory arrest on cerebral oxygen metabolism and cerebrospinal fluid electrolyte composition in dogs. J. Neurosurg. 39: 199-205 (1974). 